ISSN 2179-6750

\title{
Avaliação do estado nutricional de gestantes atendidas em uma unidade de estratégia de saúde da família de Rio Paranaíba, Minas Gerais
}

\author{
Juliana Nunes Ferreira de Alencar
}

\begin{abstract}
Resumo
Durante a gestação ocorrem mudanças fisiológicas, metabólicas e alterações das necessidades nutricionais. No primeiro trimestre, a saúde do bebê irá depender do estado nutricional prégestacional da mãe, incluindo a demanda energética e também de vitaminas, minerais e oligoelementos. O segundo e terceiro trimestres integram outra etapa para a gestante, em que as condições ambientais também vão exercer influência direta no estado nutricional do feto. Este trabalho propôs avaliar o estado nutricional das gestantes atendidas na Estratégia de Saúde da Família (ESF)-São Francisco do município de Rio Paranaíba - MG. Foram coletas informações do cartão das gestantes: peso, altura, idade gestacional e pressão arterial para classificação do estado nutricional. Trata-se de uma pesquisa de caráter transversal e observacional, sendo composta por todas as gestantes que faziam acompanhamento na unidade no período de abril a julho de 2016, e que aceitaram participar da pesquisa. As gestantes atendidas possuíam faixa etária de 16 a 35 anos e a idade gestacional dessas variava de 4 a 42 semanas. Foram avaliadas 39 gestantes, das quais 11 apresentavam baixo peso, 13 gestantes eutróficas, 5 gestantes com sobrepeso e 10 gestantes com obesidade. Em relação a altura uterina $44 \%$ das gestantes apresentaram medida adequada, $4 \%$ abaixo do desejado e as demais acima do desejado. A maioria das gestantes apresentavam pressão arterial normal $120 \times 80 \mathrm{mmHg}$, e apenas $8 \%$ das gestantes apresentavam pressão arterial $140 \times 80$ $\mathrm{mmHg}$. Aquelas gestantes diagnosticadas com risco nutricional foram encaminhadas para $\mathrm{o}$ atendimento individualizado no Ambulatório de Atenção Nutricional - UFV/CRP. Ao analisar a classificação do estado nutricional das gestantes foi observado que a maioria destas se apresentam com estado nutricional inadequado (baixo peso, sobrepeso e obesidade), o que evidencia a necessidade de um nutricionista atuando e auxiliando na educação alimentar durante a gravidez.

Descritores: Gestantes; Avaliação Nutricional; Estado Nutricional
\end{abstract}

